\title{
PROCESSO DE CONSTRUÇÃO E CALIBRAÇÃO DE UMA LOUSA DIGITAL DE BAIXO CUSTO
}

\section{CONSTRUCTION AND CALIBRATION PROCESS OF A LOW COST DIGITAL WHITEBOARD}

\author{
Thiago Lessa dos Santos Melo ${ }^{1}$ \\ Isnaldo Isaac Barbosa ${ }^{2}$ \\ Arlyson Alves do Nascimento ${ }^{3}$
}

\begin{abstract}
RESUMO: No ano de 2018 discutíamos como as novas tecnologias poderiam auxiliar o professor de Matemática no processo de ensino-aprendizagem. Dentre os recursos disponíveis naquele momento nos deparamos com o processo de construção de uma lousa digital de baixo custo, projeto do norte-americano Johnny Lee (Lee, 2018), o qual descreve um procedimento e um programa de código aberto para a devida calibração da lousa. Com base neste projeto desenvolvemos e replicamos a lousa com os recursos disponíveis no mercado brasileiro com um custo final de $R \$ 120,00$. Tal produto educacional foi explorado desde então em algumas escolas do estado de Alagoas com o objetivo de criar um ambiente colaborativo favorecendo a construção do conhecimento matemático em sala de aula. No início do ano de 2020 o mundo começou a conviver com a Pandemia do SARS-CoV-2 (COVID-19). Dentre as mudanças impostas por esta pandemia está a necessidade de utilização de recursos tecnológicos para a ministração das aulas. Diante desta situação, foi oportuno replicar o processo de construção e calibração de uma lousa digital de baixo custo para que outros professores pudessem, mesmo através do ensino remoto, possibilitar o ambiente colaborativo onde os alunos pudessem fazer uso de conhecimentos prévios de matemática para a calibração e confecção de uma lousa digital própria.
\end{abstract}

PALAVRAS-CHAVE: Lousa Digital. Ensino de Matemática. Software.

\begin{abstract}
In 2018, we discussed how new technologies could help the Mathematics teacher in the teaching-learning process. Among the resources available at that time, we came across the process of building a low-cost digital whiteboard, a project by the American Johnny Lee (Lee, 2018), which describes a procedure and an open source program for the proper calibration of the board. Based on this project, we developed and replicated the slate with the resources available in the Brazilian market at a final cost of $R \$ 120.00$. This educational product has been explored since then in some schools in the state of Alagoas with the aim of creating a collaborative environment favoring the construction of mathematical knowledge in the classroom. In early 2020, the world began to live with the SARS-CoV-2 (COVID-19) pandemic. Among the changes imposed by this pandemic is the need to use technological resources for teaching classes. Given this situation, it was opportune to replicate the process of construction and calibration of a low-cost digital whiteboard so that other teachers could, even through remote teaching, enable a collaborative environment where students could make use of prior knowledge of mathematics for calibration and making its own digital whiteboard.
\end{abstract}

KEYWORDS: Digital Whiteboard. Mathematics teaching. Software.

\footnotetext{
${ }^{1}$ Instituto Federal de Alagoas. E-mail: thiago.melo@ifal.edu.br

(1) https://orcid.org/0000-0001-6204-9318

2 Universidade Federal de Alagoas. E-mail: isnaldo@pos.mat.ufal.br

(iD) https://orcid.org/0000-0003-3147-1780

${ }^{3}$ Instituto Federal de Alagoas. E-mail: arlyson.nascimento@ifal.edu.br

(D) https://orcid.org/0000-0002-0631-3273
} 


\section{ENSIN@UFMS 2021}

ISSN 2525-7056

\section{Introdução}

Este trabalho teve início em 2018 para se tornar ao final do mesmo ano o produto educacional de uma dissertação do PROFMAT. A proposta do trabalho original era investigar o uso de recursos digitais como meios para tornar o ambiente de sala de aula colaborativo. Durante a construção da parte teórica deste trabalho tivemos contato com um projeto de construção de uma Lousa Digital (LD), que é uma ferramenta de grande utilidade para ambientes educacionais e empresariais por adicionar atividades e recursos do computador para as lousas tradicionais, apresentando uma sensibilidade ao toque. Daí, o motivo de ser considerada um dispositivo de entrada e saída de dados. Sua denominação varia conforme o fabricante e a região, podendo também ser chamada de quadro digital, quadro interativo, lousa interativa ou painel interativo.

Segundo Hervás et al. (2010, p. 204, tradução nossa) "O primeiro quadro interativo foi fabricado pela SMART Technologies Inc. em 1991, reconhecendo seu enorme potencial como uma ferramenta para aprender e apresentar novos conteúdos". Atualmente, existem muitos tipos, que variam de modelo, tamanho, marca e preço, mas, basicamente, a lousa digital funciona com três equipamentos: a lousa propriamente dita, um computador e um projetor. Inclusive, alguns modelos já possuem computador e/ou projetor integrado.

Construímos nossa primeira LD ainda em 2018 e esta foi utilizada durante a defesa da dissertação de mestrado do PROFMAT.

Figura 1. LD em funcionamento

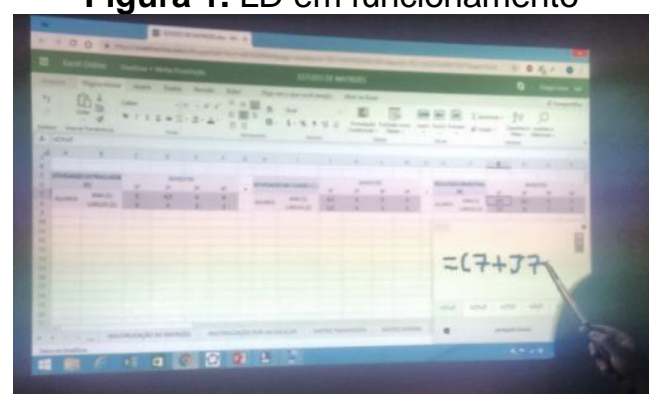

Fonte: Os autores

A proposta deste trabalho é que o professor e/ou os próprios alunos sejam capazes de construir lousas digitais e, desta forma, observar a utilização da Matemática para a resolução de um problema real. O ensino médio atual não tem sido muito atrativo para a permanência dos estudantes conforme SCHWARTZMAN, 2021, isso ocorre quando não 
existe ligação entre aquilo que se aprende e o cotidiano dos estudantes. Conforme REIS, 2017:

\begin{abstract}
A perspectiva do ensino de conceitos matemáticos com vistas ao desenvolvimento do pensamento teórico evidência grandes avanços nas concepções de aprendizagem matemática. Não apenas contribui com elementos teóricos sobre o desenvolvimento do pensamento em ascensão, o que permite justificar diferentes contextos no processo de ensino, como também orienta o processo de aprendizagem por um novo caminho, subsidiando a necessidade de romper com a aprendizagem repetitiva. (REIS, 2017, p. 187).
\end{abstract}

A utilização da lousa digital propõe promover uma interação diferenciada entre o professor e os alunos, mas, o ganho na construção de tal recurso educacional ultrapassa este fato. A participação efetiva dos estudantes na confecção das ferramentas e na calibragem do dispositivo devem causar uma aproximação significativa daquilo que se aprende em sala de aula com esta oportuna solução tecnológica.

\title{
Uma Lousa Digital de Baixo Custo
}

Os benefícios das lousas digitais para a sala de aula permitem repensar o modelo de educação utilizado e as perspectivas de futuro para o nosso ensino. Pois, seu caráter diferenciado e inovador, estimulam o interesse e a participação dos discentes. Neste período de aulas remotas a confecção individual de uma LD possibilita, mesmo em um ambiente virtual, um espaço colaborativo onde os próprios estudantes têm oportunidade de trocar experiências e as intervenções do professor, no nosso caso professor de Matemática, demonstram-se oportunas. Por outro lado, muitas escolas ainda não puderam adquirir o produto, por não possuírem recursos financeiros suficientes para um investimento desse tipo. A ideia desse artigo é construir uma Lousa Digital de Baixo Custo (LDBC) acessível à maioria das escolas e capaz de criar um ambiente que possibilite a construção coletiva do conhecimento na sala de aula. O projeto foi elaborado pelo cientista Johnny Chung Lee, utilizando um controle do Nintendo Wii (wiimote) e alguns outros itens. Para Lee (2018, tradução nossa):

Como o wiimote pode rastrear fontes de luz infravermelha (IR), você pode rastrear canetas que tenham um LED na ponta. Ao apontar um wiimote em uma tela de projeção ou em uma tela de cristal líquido, você pode criar quadros interativos ou tablets de baixo custo. (LEE, 2018, tradução nossa)

Os recursos utilizados no projeto original apresentado em (Lee, 2018):

1. Wiimote; 
2. LEDS Vishay TSAL6400s funcionando a 100mA, mas muitos outros LEDs também funcionam (este LED é utilizado na construção da "caneta").

A seguir, conheceremos os materiais necessários para o desenvolvimento do projeto da LDBC que construímos desde 2018.

\section{Materiais Necessários}

Considerando que a maioria das escolas devem possuir ao menos um computador e um projetor, vejamos o que mais será preciso para complementar o projeto:

1. Uma caneta de infravermelho: Caneta responsável pela emissão de radiação infravermelha, a ser lida pela câmera do controle Wii Remote. Essa caneta pode ser comprada ou confeccionada, utilizando-se de alguns materiais básicos:

a) Um LED emissor de infravermelho;

b) Uma bateria ou pilha AA ou AAA;

c) Uma chave liga/desliga;

d) Fios para fazer as conexões;

e) Um tubo para armazenar os componentes

Durante o projeto da caneta, observou-se que, para o bom funcionamento:

$\rightarrow$ Sobre a alimentação do circuito: a bateria de alimentação deve possuir uma capacidade de atender a voltagem máxima do LED infravermelho, o que pode acabar acarretando o uso de mais de uma pilha AA ou AAA de 1,2V (considerando que essas pilhas têm uma voltagem mínima de 0,8V);

$\rightarrow$ Inclusão de um resistor: não é regra, mas pode ser utilizado um resistor para aumentar a vida útil da bateria e do LED infravermelho;

$\rightarrow$ Polaridade do LED infravermelho: atentar-se que o fio mais curto é o negativo (ânodo) e o mais longo é o positivo (cátodo);

$\rightarrow$ Escolha do LED infravermelho: prefira os LEDs infravermelhos com uma boa potência de emissão de infravermelho e um maior ângulo de propagação, para possibilitar uma melhor visibilidade da câmera do WII REMOTE; 
$\rightarrow$ Em relação à junção dos materiais: pode ser realizada com fita isolante ou solda, porém o uso da solda dá mais qualidade à confecção da caneta. A Figura 2 ilustra o circuito para a interligação desses elementos.

Destacamos que esta não é a única forma de deixar o dispositivo funcionando e a discussão sobre a melhor forma de construir este dispositivo é uma boa oportunidade de promover uma discussão produtiva com os estudantes.

Figura 2. Simulação de circuito

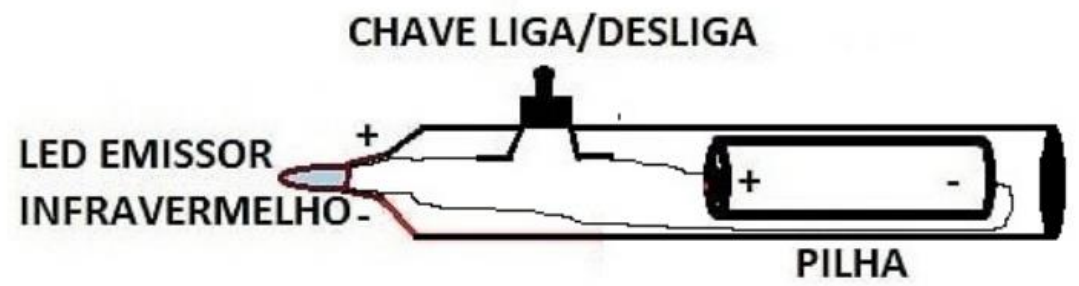

Fonte: Os autores

Para visualização da radiação infravermelha do LED, que está fora do espectro visual do olho humano, uma câmera de celular pode ser de grande valia para avaliar o perfeito funcionamento da caneta.

Estima-se um custo em torno de $\mathrm{R} \$ 10,00$ para confecção dessa caneta (este valor pode variar dependendo da região do país em que sejam comprados os componentes).

2. Um adaptador Bluetooth (caso o computador não possua bluetooth interno): A tecnologia bluetooth é um tipo de rede sem fio presente na maioria dos equipamentos modernos e será utilizada para comunicação entre o controle do Wii e o computador. Alguns modelos de computadores podem não possuir essa tecnologia de fábrica, daí a necessidade do adaptador ilustrado na Figura 3.

Figura 3. Adaptador

Fonte: Os autores

Esse adaptador é encontrado em média por $\mathrm{R} \$ 15,00$. 
3. Um controle Wii Remote: Informalmente conhecido como wiimote, é o controle do console Wii da Nintendo. Trata-se de um dispositivo sem fio, que possui uma câmera capaz de detectar LEDs emissores de infravermelho e usa a tecnologia Bluetooth para comunicação, ilustrado na Figura 4.

Figura 4. Controle Wii Remote

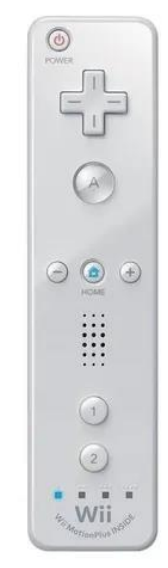

Fonte: https://www.mercadolivre.com.br/controle-joystick-sem-fio-nintendo-wii-remote-pluswhite/p/MLB15123412

Seu custo médio é de $\mathrm{R} \$ 80,00$.

4. Um software (ou programa): Considerado "o cérebro" dentre todos os elementos da LDBC, cabe ao software interpretar as informações obtidas pelo controle Wii Remote e possibilitar a interação do usuário com os programas existentes no computador. No projeto original, proposto por Lee (2018), o software construído foi o Wiimote Whiteboard, com uma interface e recursos suficientes para o funcionamento da LDBC, mas com características mais simples e limitadas. Por esse motivo, optamos pela série Smoothboard do Boon Jin, que possui capacidade para uso de até duas canetas, dois wiimotes, além da possibilidade de compartilhamento e interação com smartphones, tablets e outros dispositivos com navegador HTML5, contribuindo para colaboração em sala de aula. Por outro lado, apesar do acesso gratuito a todas as funcionalidades, o Smoothboard exibe uma mensagem, Smoothboard Air Unregistered, para as versões não registradas, o custo do registro do produto completo é de US $\$ 49,99$ (quarenta e nove dólares americanos e 99 centavos).

Com isso, observamos que os valores dos componentes da LDBC estão bem abaixo das LD profissionais, consolidando a ideia do projeto inicial de ser uma ótima alternativa de 
baixo custo. Resta entender como deve funcionar coletivamente essas ferramentas para uma boa interação usuário-lousa.

\section{Funcionamento}

O processo de funcionamento da lousa digital de baixo custo baseia-se principalmente em um componente, o controle Wii Remote da Nintendo. Segundo Lee (2018, tradução nossa): "Ele contém uma câmera infravermelha de 1024x768 com rastreamento de blob de hardware integrado de até 4 pontos a $100 \mathrm{~Hz}$.". Isso significa que a câmera do wiimote possui uma boa resolução de imagens e é capaz de acompanhar o movimento de um a quatro emissores de infravermelho. Esse infravermelho pode ser emitido por um LED acoplado a uma caneta, responsável por movimentar-se à frente da superfície de projeção. O wiimote ao fazer a leitura desse sinal transmite imediatamente ao computador, onde o software interpretará a informação em termos de coordenadas e relacionará ao movimento do cursor do mouse, por meio de uma transformação geométrica. Com isso, é possível tornar qualquer superfície em uma área interativa. A Figura 5 ilustra bem como funciona a comunicação entre os elementos do projeto.

Figura 5. Esquema de comunicação

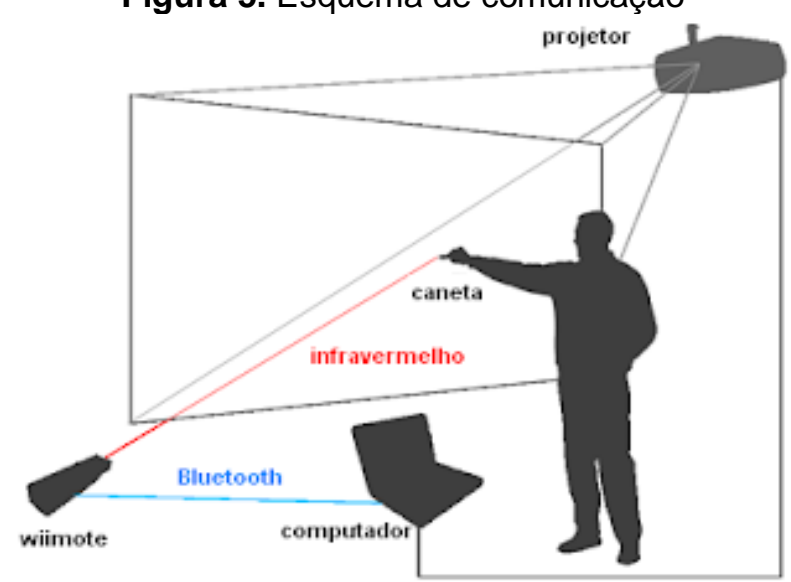

Fonte: http://lab-entremeios.blogspot.com/2011/03/lousa-digital-de-acesso-remoto-e-mesa.html

Na Figura 5, observa-se a importância do usuário identificar a melhor posição para o controle wiimote, pois a colocação do usuário diante da superfície de projeção e o campo de visão horizontal de aproximadamente 45을 de sua câmera, podem dificultar 0 reconhecimento do sinal emitido pela caneta. Além disso, o uso de uma superfície sensível a reflexos ou luminosidade solar podem provocar um mau reconhecimento da câmera. Por 


\section{ENSIN@UFMS 2021}

ISSN 2525-7056

isso, recomenda-se ao usuário atentar-se para todas as características do ambiente, além de realizar adequadamente a calibração, configuração e instalação do software, conforme será visto a seguir.

\section{Instalação do software}

O software escolhido para ilustrar as atividades na LDBC é o Smoothboard Air With Duo, uma junção do Smoothboard Air e do Smoothboard 2. Seus recursos comportam ferramentas para auxiliar nas atividades da lousa e para incentivar a colaboração na sala de aula. Sua instalação necessita de alguns requisitos do computador:

- Sistema operacional Windows (Windows 7);

- Processador de 1,6 GHz e superior (processador dual core recomendado);

- Microsoft.Net Framework 3.5 SP1

A instalação do programa é baseada em quatro etapas extremamente simples: a aceitação dos termos de uso do software; a confirmação dos elementos do software a serem instalados, possibilitando a inclusão de um atalho ao menu iniciar; a escolha do local de armazenamento e a realização da instalação propriamente dita, ativada pelo botão INSTALAR. Daí, findada essa etapa, é só conhecer melhor o programa e desfrutar de todos os seus recursos disponíveis. A Figura 6 nos dá um primeiro contato com esse programa, através da barra de ferramentas flutuante e da janela principal.

Figura 6. Janela e barra de ferramentas do programa

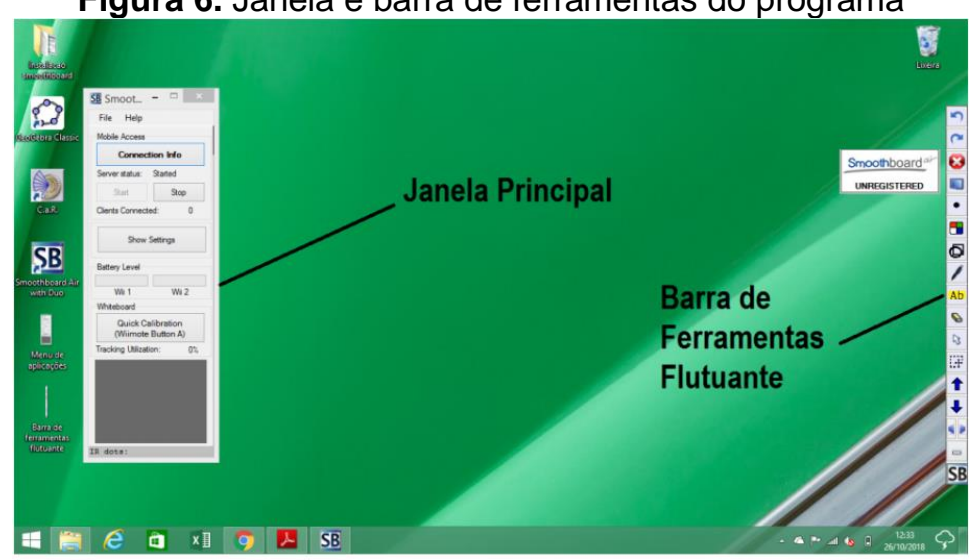

Fonte: Os autores 


\section{Configurando o software}

A partir de agora, o nosso objetivo é configurar as principais funcionalidades do software, visando obter os melhores resultados no uso da LDBC. Entretanto, observaremos que excetuando a comunicação wiimote e computador, que é realizada no início da aplicação, na janela SmoothConnect, as demais funcionalidades serão encontradas na janela principal, Figura 7, ou a partir dela.

Figura 7. Janela principal

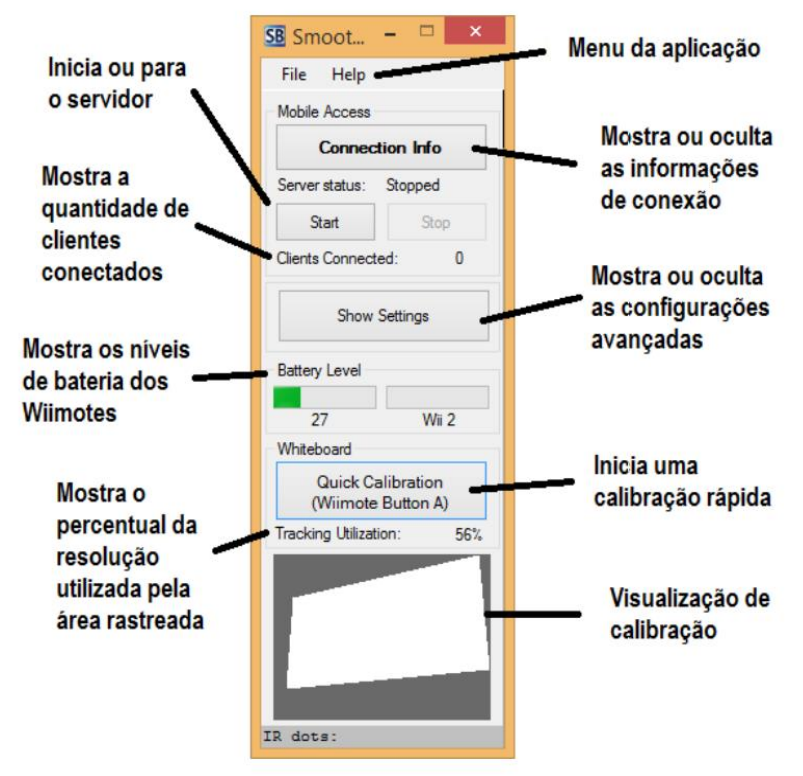

Fonte: Os autores

1. Comunicação bluetooth entre o wiimote e o computador: esse processo talvez seja 0 primeiro passo a ser realizado com o software, e ocorre ao pressionar simultaneamente os botões 1 e 2 do wiimote, onde o carregamento será realizado na janela SmoothConnect, conforme ilustra a Figura 8.

Figura 8. Janela SmoothConnect
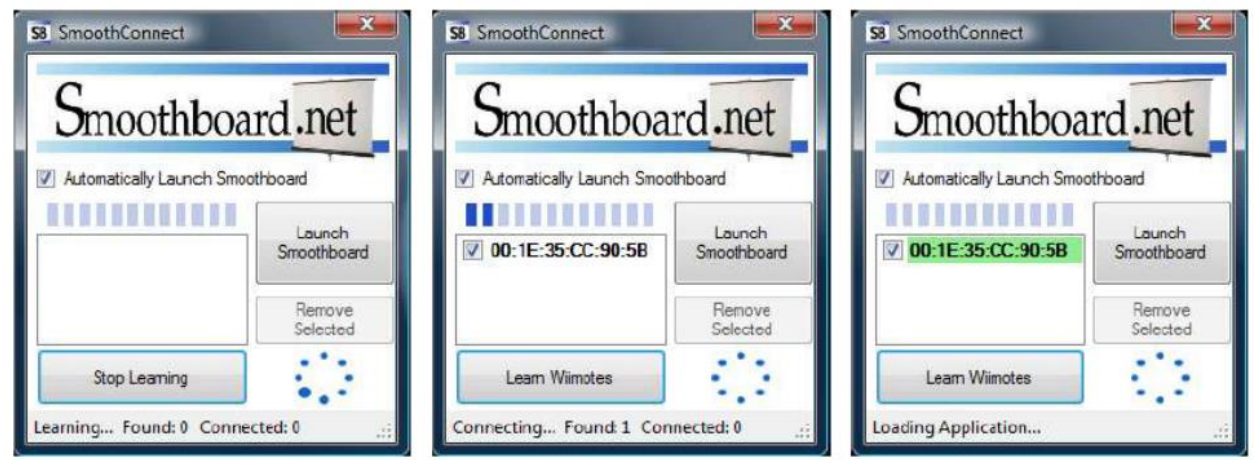

Fonte: Os autores 


\section{ENSIN@UFMS 2021}

ISSN 2525-7056

Nesse processo de procura, descoberta e conexão, a faixa esverdeada confirma o sucesso do vínculo entre os dispositivos. Por outro lado, caso o usuário decida utilizar um controle wiimote adicional, deverá acessar a janela principal, Show Settings, guia General e escolher a opção Twoo wiimotes. Daí, a comunicação será realizada com cada controle especificamente.

2. Calibração: Uma das principais etapas, a calibração será responsável por consolidar ou não a posição do wiimote escolhida pelo usuário. Funciona em quatro pontos, organizados em cada canto da tela de projeção, sendo exibido um por vez. Acionamos através da opção Quick Calibration, presente na janela principal, vista na Figura 7, ou por meio do botão $A$ do controle do Wii Remote. A Figura 9 exibe a tela de calibração.

Figura 9. Tela de calibração

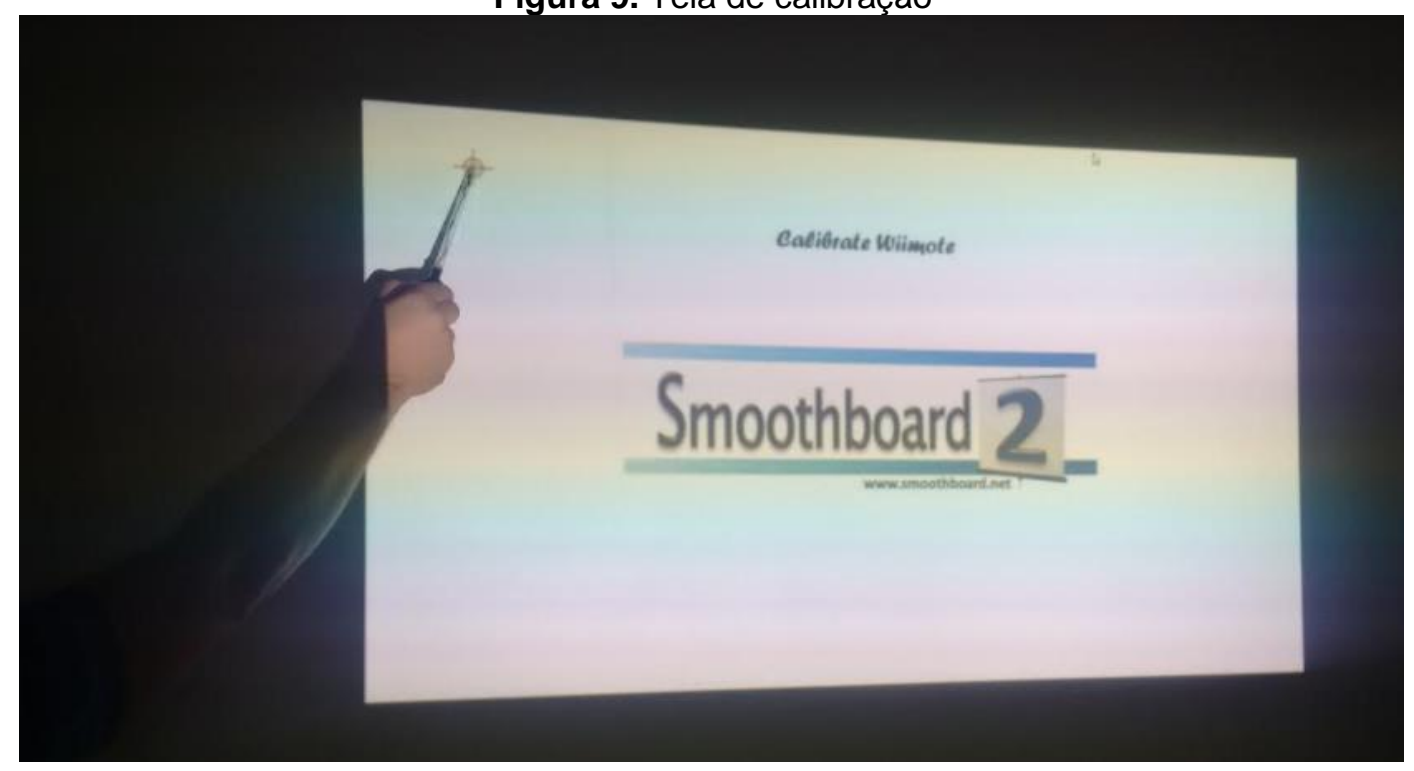

Fonte: Os autores

Presentes na janela principal, Figura 7, algumas ferramentas, podem auxiliar na otimização dessa calibração:

a) Visualizador de calibração: nessa ferramenta o usuário verifica se a região branca está presente em sua totalidade na área retangular escura, a ideia é garantir a leitura da caneta pelo wiimote em qualquer ponto da tela.

b) Utilização de rastreamento (tracking utilization): essa informação possibilita analisar se toda a resolução da câmera do Wii está sendo utilizada, de acordo com a área de projeção 


\section{ENSIN@UFMS 2021}

ISSN 2525-7056

capturada na calibração. Logicamente, quanto maior a porcentagem, melhores são os níveis de interação na LDBC.

3. Janela Informações de Conexão: é responsável por permitir o compartilhamento e a interação das ações da lousa com outros dispositivos (tablets, smartphones, por exemplo). Através dessa ferramenta, conforme Figura 10, os alunos podem obter um endereço IP diretamente ou por um QR code fornecido pelo programa. Ao acessar esse endereço IP em seus navegadores e incluírem o número PIN informado, seus dispositivos irão firmar uma conexão com a LDBC. Daí, todas as atividades realizadas na lousa serão simultaneamente vistas em seus dispositivos e, não só isso, os alunos poderão interagir individualmente com seus dispositivos, pois suas modificações serão também refletidas na LDBC. A exibição ou ocultação da janela Informações de Conexão se dá pelo botão Connecting Info, da janela principal, Figura 7.

Figura 10. QR Code

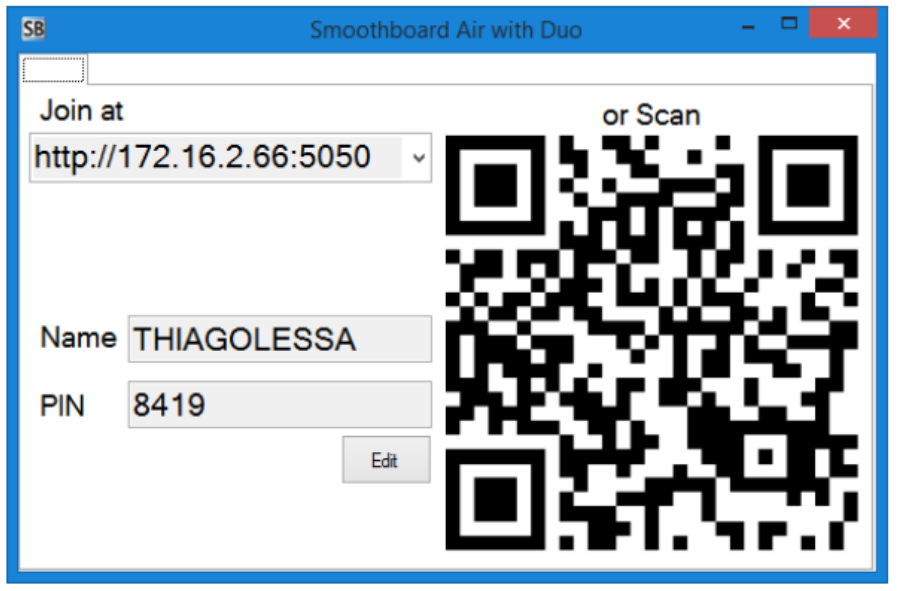

Fonte: Os autores

Esse compartilhamento com outros dispositivos pode ser restringido através do Painel de Controle de Acesso. Para acessá-lo o usuário deve clicar em Hide Settings na janela principal, guia General, aba Mobile Access, botão Access Control Panel. Também é possível iniciar ou parar o compartilhamento através dos botões Start ou Stop, respectivamente, presentes na janela principal.

4. Acompanhamento dos níveis de bateria: essa é outra ferramenta de grande utilidade por permitir ao usuário a verificação constante dos níveis de bateria do wiimote. Com isso, o 
usuário consegue se planejar para realizar a troca das pilhas e evitar interrupções, durante suas apresentações na LDBC.

Uma vez preparado todo o cenário para implementação do programa da lousa digital de baixo custo, chegou o momento de o usuário conhecer melhor as ferramentas práticas disponíveis. Para isso, daremos um enfoque na Barra de Ferramentas Flutuante, cujo objetivo é auxiliá-lo nas atividades desenvolvidas na lousa.

\section{O Aspecto Prático do software}

Tida como uma ferramenta para auxiliar nas ações do usuário na LDBC, a Barra de Ferramentas Flutuante traz à tona um grande diferencial no aspecto prático da lousa digital, quando comparada ao quadro ou lousa comum. Essa barra envolve ferramentas desde as mais tradicionais, como a caneta e o apagador, até as mais sofisticadas, como desfazer, refazer, reduzir, aumentar ou mover objetos na lousa, onde as ações podem ser todas registradas e impressas para o público-alvo. A Figura 11 traz uma melhor visão sobre essa barra:

Figura 11. Barra de ferramentas

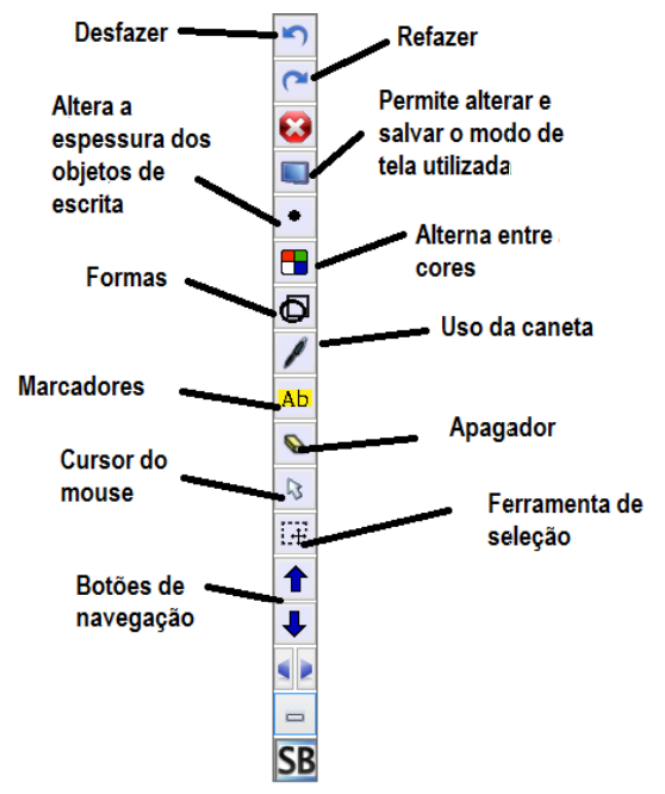

Fonte: Os autores

A seguir, iremos destacar as principais funcionalidades dessa barra:

1. Divisão de tela: com essa ferramenta é permitida a interação de duas pessoas simultaneamente na lousa, cada um com sua caneta de infravermelho. Em uma sala de 
aula, por exemplo, os alunos podem resolver, paralelamente, um determinado problema proposto na lousa e partilhar ou discutir as diferentes soluções atingidas. Em uma apresentação, dois usuários podem expor, simultaneamente, ideias opositivas e permitirem uma comparação do público, vislumbrando uma tomada de decisões. Com isso, abre-se um leque de opções e ideias para o estímulo à colaboração entre os membros de um grupo qualquer. Esse recurso pode ser acessado a partir da barra de ferramentas flutuante, botão tela, Figura 11.

2. Comentando, marcando e manipulando comentários e marcações em documentos ou apresentações: os botões apagador, marcador, selecionar e caneta são ferramentas capazes de enriquecer o conteúdo explorado, pois se sobrepõem a qualquer objeto presente na tela e criam a sensação de manuseio de uma lousa comum munida de alguns recursos. Com eles é possível destacar pontos chaves, comentar em apresentações de slides, selecionar, mover e apagar comentários, criando uma série de observações que podem ser salvas e compartilhadas com o público-alvo.

3. Instantâneo de parte ou de todas as ações na lousa: essa ferramenta auxilia o usuário a manter um histórico das observações realizadas no item anterior, durante uma apresentação ou aula interativa. Além disso, unidas aos recursos de partilhar e imprimir as ações na lousa dispensa o ato de escrever e possibilitam aos alunos maior concentração e participação no seu aprendizado e dos demais colegas.

4. O botão grade: obtido a partir da expansão do botão tela, na barra de ferramentas flutuante, Figura 11, este botão possibilita a inserção de linhas verticais e horizontais na lousa comum. Com isso, é possível explorar conceitos de áreas de figuras geométricas ou realizar um estudo de gráficos em um sistema de eixo previamente construído (o botão forma auxilia na construção dos eixos direcionais).

Dessa forma, observamos que a LDBC fornece uma série de benefícios para a sala de aula, que podem ser complementados, pelo professor, com outros aplicativos específicos, seja para o estudo da geometria (como é o caso do Geogebra), para conversão da escrita manual para digital, tornando a escrita mais legível (Ferramenta de Inserção de Texto Plugin do Google Chrome), dentre outras ferramentas disponíveis na plataforma Windows ou na própria Web. 


\section{Aplicabilidade da Construção da Lousa Digital na Sala de Aula}

No entanto, os benefícios da construção de uma Lousa Digital própria, na sala de aula, não se restringem apenas ao seu baixo custo, mas também à compreensão do potencial existente por trás da ferramenta para a exploração de conteúdos matemáticos.

Nesse sentido, a nossa Base Nacional Comum Curricular revela a importância em aplicar a matemática em diferentes contextos e enaltece o uso das tecnologias digitais como meio para investigação matemática, sendo competência específica do currículo de Matemática e suas Tecnologias:

\footnotetext{
Utilizar estratégias, conceitos e procedimentos matemáticos para interpretar situações em diversos contextos, sejam atividades cotidianas, sejam fatos das Ciências da Natureza e Humanas, das questões socioeconômicas ou tecnológicas, divulgados por diferentes meios, de modo a contribuir para uma formação geral. (BRASIL,2018, p. 534).
}

Nossa proposta, aqui, é utilizar o processo de calibração, realizado pelo software, como um meio de aplicar a matemática em turmas do ensino médio e trazer para o estudante a possibilidade de ser parte do processo de construção da sua própria Lousa Digital, pensando como desenvolvedores.

$\mathrm{Na}$ verdade, a calibração do wii remote consiste especificamente em um mapeamento de 4 pontos do plano físico (plano do infravermelho da caneta) para o plano virtual (plano do cursor do mouse). Esse processo de sincronização entre os dois planos (físico e virtual) é realizado por meio de uma técnica matemática chamada de Transformação Geométrica. Graças a essa técnica é possível mover a caneta e o cursor ao mesmo tempo e no mesmo ponto na tela de projeção. Nas Figuras 12 e 13 podemos observar que aos pontos A', B', C' e D' do plano físico correspondem, respectivamente, os pontos $A, B, C$ e $D$ do plano virtual. 
Figura 12: Plano Físico (Visão do Wii Remote do Plano do Infravermelho da Caneta)

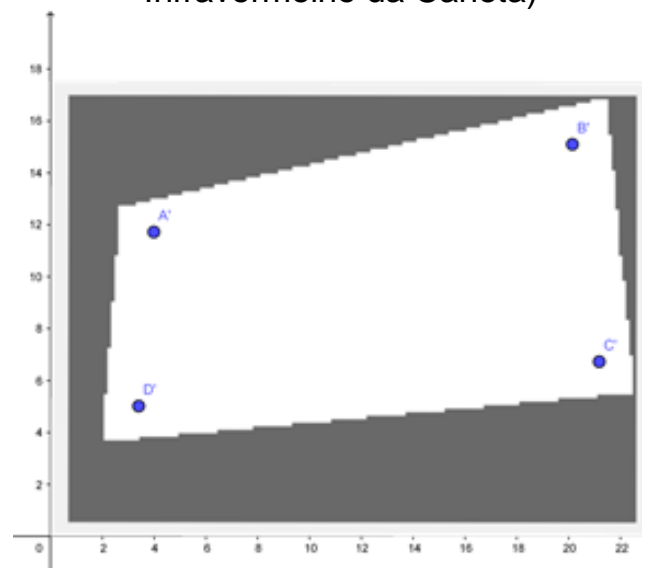

Fonte: autores

Figura 13: Plano Virtual (Plano do Cursor do Mouse)

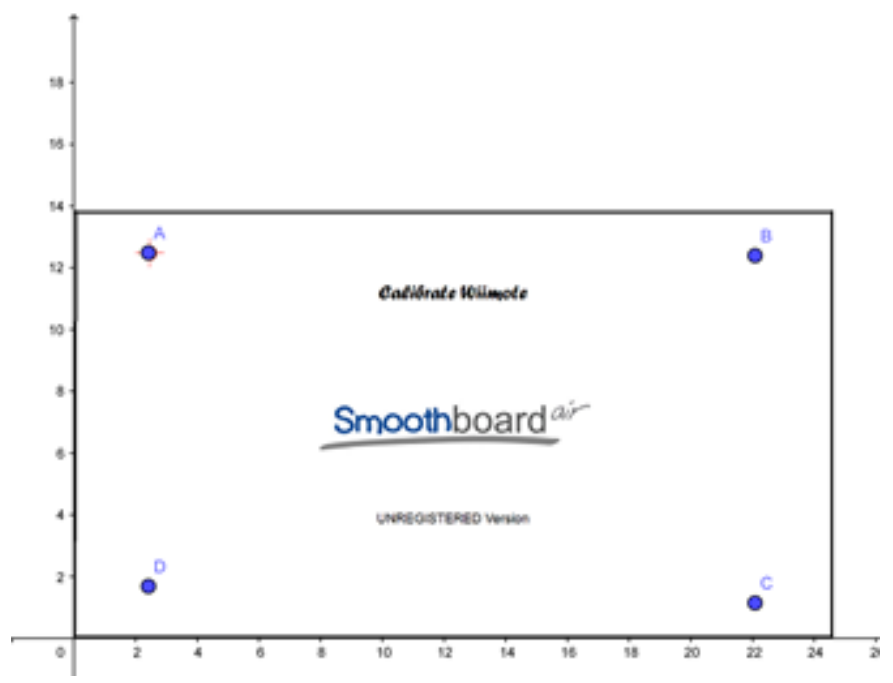

Fonte: Os autores

Mas o que seria uma transformação geométrica? Uma Transformação Geométrica é "uma correspondência, um a um, entre pontos de um mesmo plano ou de planos diferentes.". Isto é, para cada ponto do plano físico corresponde um único ponto do plano virtual.

Abaixo ilustraremos alguns tipos de transformações geométricas produzidas no software Geogebra e que podem ser exploradas em sala de aula: 
Figura 14: Translação

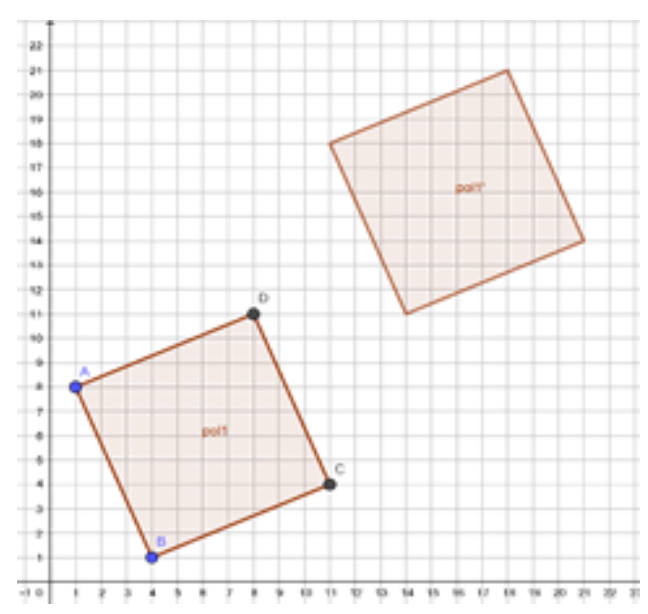

Fonte: Os autores

Figura 15: Homotetia

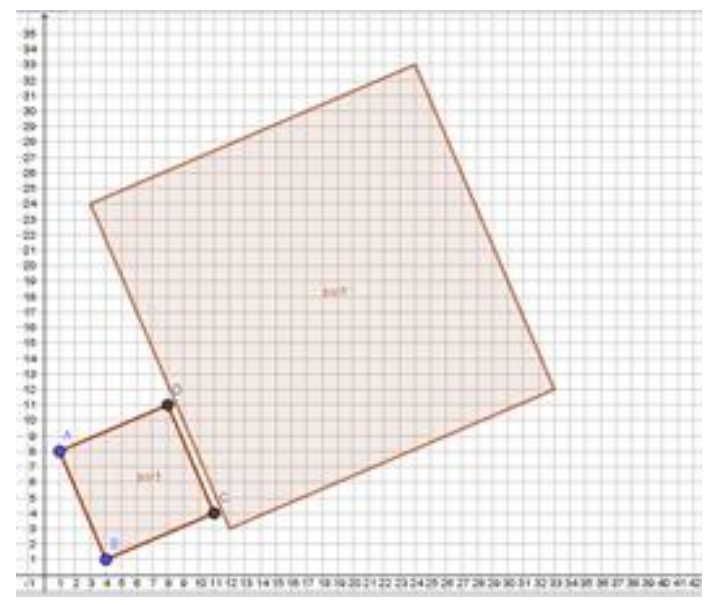

Fonte: Os autores

Figura 16: Rotação

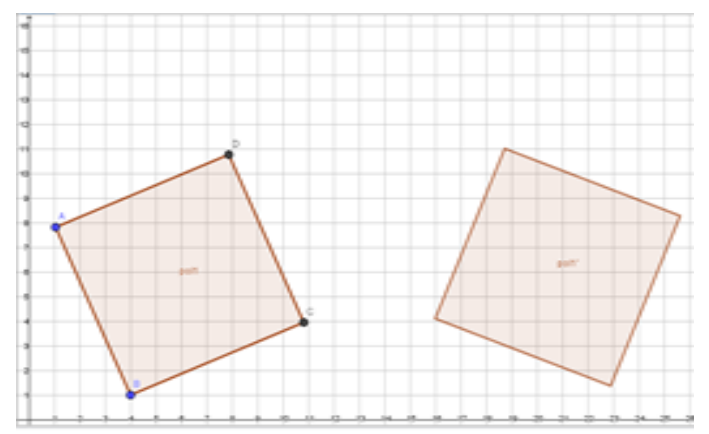

Fonte: Os autores 
Figura 17: Cisalhamento

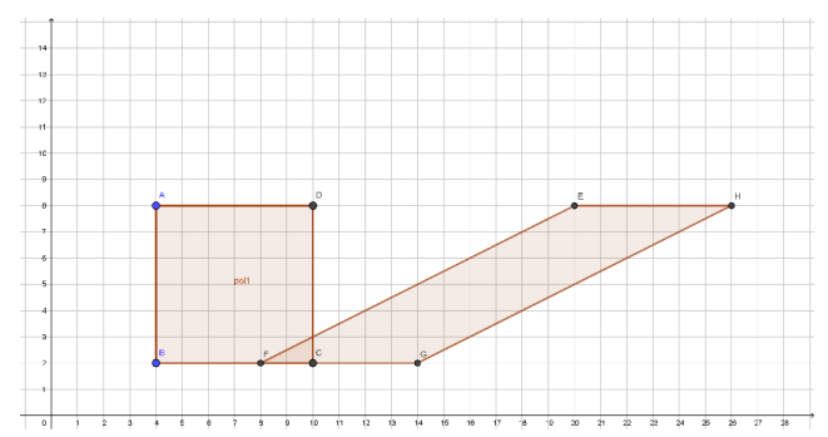

Fonte: Os autores

Essas transformações possibilitam a exploração de conteúdos como matrizes e determinantes, sistemas lineares, funções, dentre outros. Com isso, conseguimos unir Álgebra e Geometria concretizando conteúdos que por muito tempo foram entendidos como essencialmente abstratos.

Transformação Geométrica é uma técnica matemática muito utilizada na computação gráfica para transformar figuras em outras (especificamente transladar, refletir, rotacionar, dilatar), em um mesmo plano ou em planos distintos, por meio de uma correspondência biunívoca com a figura original. A título de conhecimento, sugerimos a leitura do livro Hartley e Zisserman (2004)

Outras situações, onde é possível encontrar transformações geométricas são:

- Em uma maquete de um prédio a ser construído;

- Nas escalas utilizadas na produção de mapas;

- No layout de um projeto para elaboração de circuitos elétricos ou hidráulicos de uma casa;

- No projeto para criação de móveis em uma marcenaria;

- Dentre outras.

A própria Base Nacional Comum Curricular entende as transformações geométricas como habilidade para a área de Matemática e suas Tecnologias:

(EM13MAT105) Utilizar as noções de transformações isométricas (translação, reflexão, rotação e composições destas) e transformações homotéticas para construir figuras e analisar elementos da natureza e diferentes produções humanas (fractais, construções civis, obras de arte, entre outras). (BRASIL, 2018, p.535). 


\section{ENSIN@UFMS 2021}

ISSN 2525-7056

As transformações isométricas e homotéticas são, na verdade, tipos de transformações geométricas, a primeira (isométrica) trata das transformações que preservam a mesma distância entre os pontos da figura original, enquanto a segunda (homotética) trata das transformações entre figuras semelhantes, onde uma é uma ampliação ou redução da outra, muito utilizada em escalas.

Com isso, o professor tem um leque de possibilidades e estratégias que podem ser exploradas, cujo produto, a Lousa Digital de Baixo Custo, é uma ferramenta colaborativa e com grandes recursos para o aprendizado da matemática na sala de aula, tanto durante, quanto após o seu processo de criação.

\section{Considerações Finais}

Finalizamos o trabalho do PROFMAT demonstrando a aplicabilidade da Lousa Digital como recurso educacional de baixo custo em aulas de diferentes níveis, mas o que nos chamou mais a atenção foi a facilidade com que os próprios estudantes conseguiam reproduzir a adaptar o uso da LD em suas próprias casas. A possibilidade de interagir nas aulas contribuindo dinamicamente na tela que o professor projetava foi outro ganho que merece destaque aqui.

A imagem que compartilhamos abaixo é uma situação real onde um dos autores ministrava aula fazendo uso dos recursos construídos por ele mesmo.

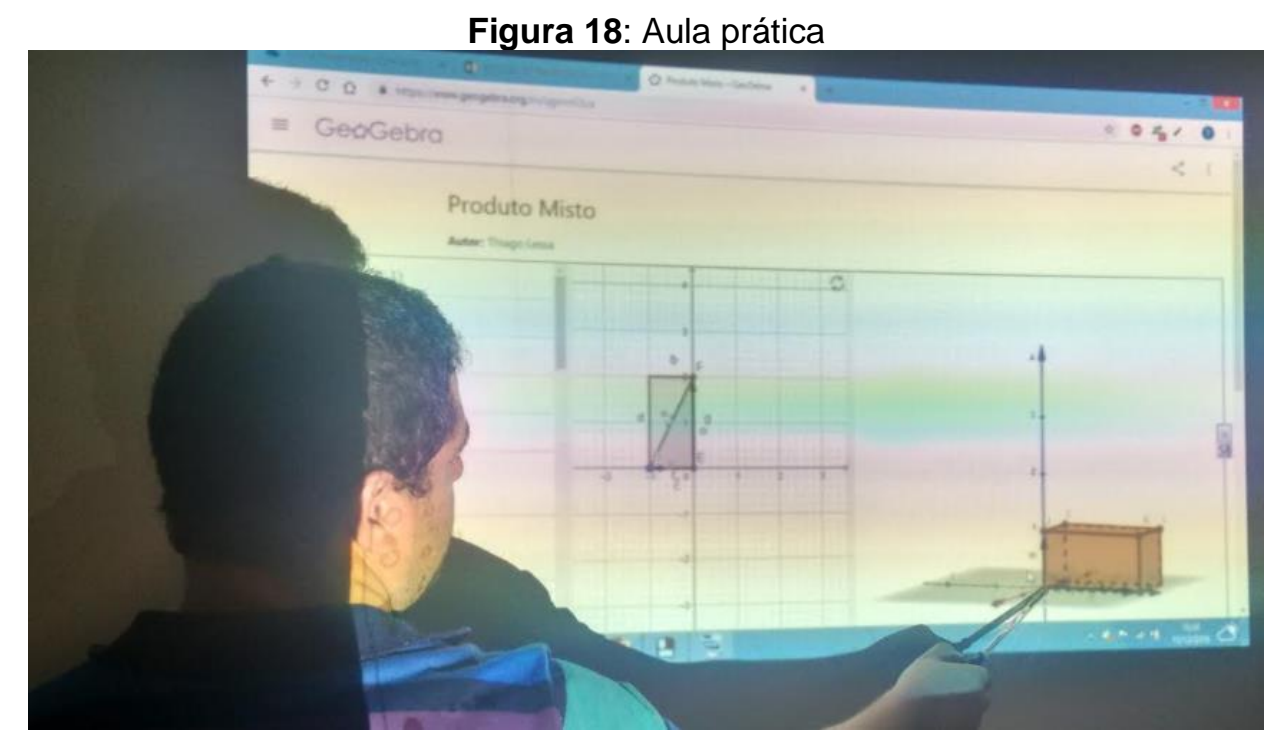

Fonte: autores

Destacaremos a seguir algumas dificuldades enfrentadas durante a construção do projeto e utilização em sala de aula. 
Para construir a caneta de IR, por exemplo, um LED de um controle velho de TV e um botão reset de um roteador (não mais utilizados e em funcionamento), podem ser uma alternativa mais acessível para os professores, já que encontrar um LED específico, com boa potência e ângulo de projeção, não é tarefa das mais simples. O LED Vishay TSAL 6400 , cujas especificações seriam mais adequadas para o projeto, não é tão simples de encontrar e o frete, a depender da região, pode acabar deixando o produto superfaturado. Uma solução para quem deseja adquiri-lo seria comprar os componentes elétricos em maior quantidade, pensando em outros projetos, ou juntar-se com um grupo de amigos com o mesmo interesse.

Por outro lado, escolha o melhor ambiente possível para sua Lousa Digital de Baixo Custo. Se o seu LED ficar mais visível ao posicionar de maneira direta para o wiimote, isto é, possuir um pequeno ângulo de propagação, então aposte em superfícies escuras ou bem pouco iluminadas. Quanto menos interferência externa você tiver no seu projeto, melhores serão os resultados.

Por último, como todo processo de mudança e evolução, a LDBC exige uma adaptação do professor não somente no uso do software, mas também na escrita com a caneta de infravermelho, no movimento de construção dos objetos geométricos, que podem ser aperfeiçoados com o tempo.

\section{Referências}

BRASIL. Ministério da Educação. Base Nacional Comum Curricular. Brasília, 2018.

HARTLEY, R.; ZISSERMAN, A. Multiple view geometry in computer vision. Second edition. Nova lorque, USA: Cambridge University Press, 2004.

HERVÁS, C. T; GONZÁLES, P; CARMEN, M. La utilización conjunta de la pizarra digital interactiva y el sistema de participación senteo: una experiencia universitaria. Pixel-Bit, Revista de Medios y Educación, Universidad de Sevilla, Sevilla, España., n. 36, p. 203214, 2010.

LEE, J. C. Projetos Wii. 2018. [Online; Acesso em: 27-agosto-2021]. Disponível em: http://johnnylee.net/.

REIS, A. Q. M. A contextualização da matemática como princípio educativo no desenvolvimento do pensamento teórico: exploração de contextos no movimento do pensamento em ascensão do abstrato ao concreto. 2017. Tese (Doutorado em Educação 
nas Ciências) - Universidade Regional do Noroeste do Estado do Rio Grande do Sul, ljuí, RS, 2017.

\section{NOTAS}

\section{IDENTIFICAÇÃO DE AUTORIA}

Thiago Lessa dos Santos Melo. Mestre em Matemática pela Universidade Federal de Alagoas (UFAL). Instituto Federal de Alagoas (IFAL), Maceió, AL, Brasil.

E-mail: thiago.melo@ifal.edu.br

ORCID: https://orcid.org/0000-0001-6204-9318

Isnaldo Isaac Barbosa. Doutor em Matemática, Associação UFAL-UFBA pelo Instituto de Matemática UFAL. Professor Adjunto. Universidade Federal de Alagoas, Maceió, AL, Brasil.

E-mail: isnaldo@pos.mat.ufal.br

ORCID: https://orcid.org/0000-0003-3147-1780

Arlyson Alves do Nascimento. Doutor em Matemática Aplicada. Professor EBTT - D IV. Instituto Federal de Alagoas (IFAL), Maceió, AL, Brasil.

E-mail: arlyson.nascimento@ifal.edu.br

ORCID: https://orcid.org/0000-0002-0631-3273

\section{AGRADECIMENTOS}

O primeiro autor agradece aos professores Dr. Arlyson e Dr. Isnaldo, coautores do trabalho, pelo incentivo e participação no projeto.

\section{FINANCIAMENTO}

Não se aplica.

CONSENTIMENTO DE USO DE IMAGEM

Não se aplica.

\section{APROVAÇÃO DE COMITÊ DE ÉTICA EM PESQUISA}

Não se aplica.

\section{LICENÇA DE USO}

Autores mantêm os direitos autorais e concedem à revista ENSIN@ UFMS - ISSN 2525-7056 o direito de primeira publicação, com o trabalho simultaneamente licenciado sob a Licença Creative Commons Attribution (CC BY-NC-SA 4.0), que permite compartilhar e adaptar o trabalho, para fins não comerciais, reconhecendo a autoria do texto e publicação inicial neste periódico, desde que adotem a mesma licença, compartilhar igual.

\section{EDITORES}

Patricia Helena Mirandola Garcia, Eugenia Brunilda Opazo Uribe, Gerson dos Santos Farias.

\section{HISTÓRICO}

Recebido em: 21/08/2021 - Aprovado em: 23/11/2021 - Publicado em: 15/12/2021.

\section{COMO CITAR}

MELO, T. S. L; BARBOSA, I. I; NASCIMENTO, A. A. Processo de Construção e Calibração de uma Lousa Digital de Baixo Custo. Revista ENSIN@ UFMS, Três Lagoas, v. 2, número especial, p. 354-373. 2021. 